\title{
Produção de metano via codigestão anaeróbia de efluentes das indústrias de arroz parboilizado e laticínios
}

As indústrias de processamento de arroz e laticínios geram efluentes com grande potencial poluidor que requerem modelos alternativos de tratamento. Nesse sentido, a codigestão anaeróbia surge como processo de tratamento preliminar capaz de fornecer energia limpa durante seus processos de fermentação. $O$ objetivo deste estudo, foi avaliar a melhor proporção de mistura dos substratos e inóculo para elevar a eficiência da produção de metano via codigestão anaeróbia com lodo da indústria de arroz (inóculo) e efluente das indústrias de laticínios e arroz parboilizado (substratos), gerados no Rio Grande do Sul, por meio de delineamento experimental com arranjo fatorial $2^{3}$, quantificando o metano gerado, através de um sistema desenvolvido com base no deslocamento de fluidos, e análises $\mathrm{pH}$ e Demanda Química de Oxigênio. O experimento ocorreu em batelada, à $35^{\circ} \mathrm{C}$ por 252 horas. A maior produção de metano, $1,50 \mathrm{dm}^{3}$, ocorreu no biodigestor que recebeu $40 \%$ de efluente de arroz, $20 \%$ efluente de laticínios e 30\% de inóculo. Quanto a remoção de Demanda Química de Oxigênio (DQO), os biodigestores que removeram maiores cargas de DQO foram, em sua maioria, os mesmos que produziram maiores volumes de metano, com remoções de até 76,74\%. Todos os pontos apresentaram acidez em suas amostras de entrada e neutralidade nas de saída. Quanto ao sistema de quantificação de gases desenvolvido no estudo, o mesmo apresentou alta eficácia, com baixo desvio padrão e coeficiente de variação.

\section{Methane production from anaerobic codigestion of wastewater from parbolized rice and dairy industries}

\begin{abstract}
The rice and dairy processing industries generate effluents with high polluting potential that require alternative treatment models. In this sense, anaerobic codigestión emerges as a preliminary treatment process capable of providing clean energy during its fermentation processes. The objective of this study was to evaluate the best mixing ratio of substrates and inoculum to increase the efficiency of methane production from anaerobic codigestion with sludge from the rice industry (inoculum) and effluent from the dairy and parboiled rice industries (substrates), generated in Rio Grande do Sul, by means of an experimental design with factorial arrangement $2^{3}$, quantifying the generated methane, through a system developed based on the displacement of fluids, and $\mathrm{pH}$ and Chemical $\mathrm{Oxygen}$ Demand analyzes. The experiment was carried out in batch at $35^{\circ} \mathrm{C}$ for 252 hours. The highest methane production, $1.50 \mathrm{dm}^{3}$, occurred in the biodigestor that received $40 \%$ of rice effluent, $20 \%$ of dairy effluent and $30 \%$ of inoculum. Regarding the removal of Chemical Oxygen Demand (COD), the biodigesters that removed the highest COD loads were mostly the same ones that produced higher volumes of methane, with removals of up to $76.74 \%$. All points showed acidity in their input samples and neutrality in the output samples. As for the gas quantification system developed in the study, it showed high efficiency, with low standard deviation and coefficient of variation.
\end{abstract}

Keywords: Cosubstrat; Inoculum; Sludge; Wastewater; Anaerobic Codigestion.

Willian Cézar Nadaleti (10)

Universidade Federal de Pelotas, Brasil http://lattes.cnpq.br/4670559561277136 http://orcid.org/0000-0002-4727-4127 williancezarnadaletti@gmail.com

\section{Vitor Alves Lourenço (iD}

Universidade Federal de Pelotas, Brasil http://lattes.cnpq.br/0540242108317748 http://orcid.org/0000-0003-3940-7812 vitor.a.lourenco@gmail.com

\section{Guilherme Pereira Schoeler}

Universidade Federal de Pelotas, Brasil http://lattes.cnpq.br/6241607536410111 guilherme.schoeler@gmail.com

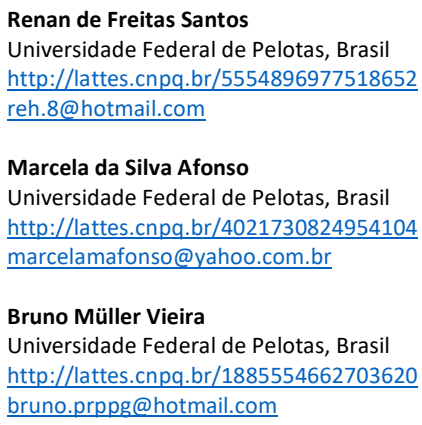

Diuliana Leandro

Universidade Federal de Pelotas, Brasil http://lattes.cnpq.br/3076528365846421 diuliana.leandro@gmail.com

Anaís França de Matos Oliveira

Universidade Federal de Pelotas, Brasil http://lattes.cnpq.br/4972641617559480 anais.franca@uol.com.br

Ivanna Franck Koschie

Universidade Federal de Pelotas, Brasil http://lattes.cnpq.br/3875700843821844 ivannafk@hotmail.com
Referencing this:

NADALETI, W. C.; LOURENÇO, V. A.; SCHOELER, G. P.; SANTOS, R. F.; AFONSO, M. F.; VIEIRA, B. M.; LEANDRO, D.; OLIVEIRA, A. F. M.; KOSCHIER, I. F.. Produção de metano via codigestão anaeróbia de efluentes das indústrias de arroz parboilizado e laticínios. Revista Ibero Americana de Ciências Ambientais, v.10, n.1, p.146-156, 2019. DOI: http://doi.org/10.6008/CBPC2179-6858.2019.001.0012 


\section{INTRODUÇÃO}

Ao longo dos últimos 40 anos a inserção de tecnologias no campo, através de máquinas, técnicas de cultivo e uso da irrigação, levaram à uma elevação nas taxas da produção agrícola no Brasil (CONAB, 2017), Segundo o The Statista Portal, o país fechou 2017 com cerca de 12,3 milhões de toneladas de arroz produzidos (STATISTA, 2018) com previsão de crescimento de $0,86 \%$ para os próximos anos (SPINOSA et al., 2016).

O crescimento do número de indústrias de processamento de arroz necessários para manter a demanda populacional, acarreta em uma maior geração de efluentes de elevada carga orgânica e níveis significativos de nitrogênio e fósforo (BASTOS et al., 2010; KUMAR et al., 2016; QUEIROZ et al., 2007; SANTOS et al., 2012). Outro importante setor da agroindústria dentro do cenário nacional é o dos laticínios, o país é um dos principais produtores do produto no mundo, tendo produzido cerca de 35 milhões de toneladas de leite e seus derivados no ano de 2017 (FAO, 2018). Sendo o Rio Grande do Sul um estado com alta produção em ambos os setores, estando em primeiro lugar no ranking de produção de arroz (IBGE, 2017) e ocupando a segunda colocação na produção de laticínios (RIO GRANDE DO SUL, 2018).

Estima-se que as indústrias de processamento de leite geram de 2,5 litros de efluente por litro de leite processado (LEKSHMISREE et al., 2016), tal efluente possui é altamente poluidor, principalmente por sua alta concentração de matéria orgânica, constituída principalmente de gordura que ocasiona uma baixa degradabilidade por meio microrganismos (HIROTA et al., 2016).

A digestão anaeróbia é uma técnica para tratamento de efluentes e produção de bioenergia através da interação de fatores da microbiota e parâmetros do reator alimentado os efluentes orgânicos aplicados ao sistema (NESHAT et al., 2017). Nesse contexto, a codigestão anaeróbia se apresenta como um processo promissor na geração de biogás (ANJUM et al., 2017), já que é onde ocorre a digestão simultânea de dois ou mais substratos que promove elevação da estabilidade e eficiência do sistema (MARAGKAKI et al., 2017).

Para máximo aproveitando a codigestão anaeróbia é preciso a seleção de um cosubstrato adequado para o processo, já que uma escolha inadequada pode resultar em declínio significativo das taxas de degradação e produção de biogás, também se faz necessário estipular a mistura ideal dos substratos de modo a obter a otimização de um substrato com outro (ANJUM et al., 2017).

Nesse sentido, o objetivo deste trabalho foi determinar as melhores proporções para a codigestão anaeróbia de lodo oriundo da indústria de arroz (inóculo) e efluente das indústrias de laticínios e de arroz parboilizado (substratos) por meio de delineamento experimental com arranjo fatorial $2^{3}$, quantificação de biogás, por meio uso de um sistema desenvolvido com base no deslocamento de fluidos, e análises de pH e Demanda Química de Oxigênio (DQO).

\section{REVISÃO TEÓRICA}

\section{Indústrias de arroz parboilizado}


O Brasil é um grande produtor e consumidor do arroz, com um consumo per capita em torno de 25 $\mathrm{kg} / \mathrm{ano}$, consolidando o grão como um grande setor da economia do país (QUEIROZ et al., 2007; SPINOSA et al., 2016). Cerca de $25 \%$ do arroz consumidos pelos brasileiros é do tipo parboilizado (PARAGINSKI et al., 2014), o beneficiamento do arroz parboilizado difere do arroz branco, pois após a retirada da casca e do farelo o grão é submetido a o encharcamento em tanques com água á $60^{\circ} \mathrm{C}$ por algumas horas e vaporização seguida de secagem. O ponto crítico da geração de efluentes ocorre justamente na etapa de encharcamento do grão, por utilizar um grande volume de água que retém propriedades do grão durante o banho (AMATO et al., 1989) Tal efluente se caracteriza por possuir alta carga orgânica e níveis significativos de nitrogênio e fósforo, a cada quilo de arroz parboilizado são gerados de 2 a 4 L de efluente (BASTOS et al., 2010; KUMAR et al., 2016; QUEIROZ et al., 2007; SANTOS et al., 2012).

O Brasil é um dos 10 maiores produtores de arroz do mundo, sendo que o estado do Rio Grande do Sul possui a maior representatividade interna do setor com $71,4 \%$ da produção nacional (IBGE, 2017; SPINOSA et al., 2016). Desse modo, de acordo com Nadaleti et al. (2018), o setor industrial brasileiro de arroz possui capacidade de promover a autossuficiência energética através de seu potencial de produção de energia.

\section{Indústrias de laticínios}

O Brasil possui a quinta maior produção de leite do mundo (RIO GRANDE DO SUL, 2018), tendo produzido cerca de 24 milhões de toneladas de leite e seus derivados no ano de 2017. O país é ainda um dos principais importadores mundiais, com previsão de crescimento de 1,8\% para 2018 (FAO, 2017; USDA, 2017). De acordo com o Atlas Socioeconômico do Rio Grande do Sul, o estado é o segundo maior produtor dentro do cenário nacional, respondendo por $13 \%$ da produção.

Assim, o setor se apresenta como uma grande fonte de efluentes, o processamento de um litro de leite gera em torno de 2,5 litros de efluente (LEKSHMISREE et al., 2016) altamente poluidor. Seu potencial de poluição se dá por seu alto teor de matéria orgânica em sua composição, com cargas elevadas de proteínas, sólidos, substâncias gordurosas e lactose (CASTRO et al., 2017; HIROTA et al., 2016).

As características do efluente são majoritariamente favoráveis à utilização de processos biológicos em seu tratamento, uma vez que a maior parte da matéria orgânica (99\%) presente nos efluentes de indústria de laticínios são biodegradáveis (CASTRO et al., 2017; KOTHARI et al., 2016), entretanto, a gordura presente em sua composição possui poder inibitório aos microrganismos, consequentemente, para a produção do biogás (GOLUNSKI et al., 2017; HIROTA et al., 2016).

\section{Produção de biogás}

O biogás é gerado por meio do processo de digestão anaeróbia, seu ciclo possui um sistema integrado entre o processo fisiológico do metabolismo microbiano e o energético (MAO et al., 2015). Qualquer tipo de 
biomassa pode ser empregada como substrato para a produção da bioenergia, desde que contenham carboidratos, proteínas, gorduras, celulose e hemiceluloses em sua composição (GRANDO et al., 2017).

Os microrganismos responsáveis pela degradação da matéria orgânica e a produção do biogás possuem alta sensibilidade a variações nas condições operacionais aplicadas, ou seja, a instabilidade do sistema resulta em redução da produção de biogás (MAO et al., 2015). Assim, se torna essencial o comprimento dos parâmetros do processo, dentre eles está a temperatura, que deve ser mantida em torno de $35^{\circ} \mathrm{C}$ para maior rendimento da produção dos gases (THAKUR et al., 2016).

A remoção de matéria orgânica pode ser quantificada através da DQO, assim como o potencial de produção de metano, já que potencial de produção do gás é diretamente proporcional a remoção de DQO (METCALF et al., 2016). O biogás consiste em uma mistura gasosa composta majoritariamente de metano e dióxido de carbono gerados a partir de águas residuais, estrume, culturas e resíduos sólidos na fermentação anaeróbia com grande aplicabilidade energética, o uso de efluentes agroindustriais é um atrativo para o mercado brasileiro no que diz respeito a codigestão anaeróbia, uma vez que o aumento do setor agrícola gera grandes volumes de subprodutos com alto risco ambiental (GAIDA et al., 2017; PAZUCH et al., 2017).

A codigestão anaeróbia ocorre através do emprego de dois ou mais substratos simultaneamente e promove maior estabilidade do processo (MARAGKAKI et al., 2017). Assim, substratos que sozinhos não apresentem características favoráveis a degradação anaeróbia, se tornam viáveis ao processo, através da associação com outras fontes de matéria orgânica que possuam características complementares e/ou capazes de garantir a diluição dos compostos inibitórios (AGDAG et al., 2007).

\section{Purificação e quantificação de biogás}

O metano é o gás com maior teor na composição do biogás, com concentrações de 40 a $75 \%$, seguido do dióxido de carbono (de 15 à 60\%) e traços de sulfeto de hidrogênio, nitrogênio, siloxanos, água, hidrocarbonetos halogenados e monóxido de carbono (RYCKEBOSCH et al., 2011). O alto teor de metano é crucial para conversão do biogás em bioenergia, enquanto o alto teor de dióxido de carbono $\left(\mathrm{CO}_{2}\right)$ interfere negativamente, já que é inerte em termos de combustão, reduzindo o poder calorifico do biogás. Um dos métodos de purificação do biogás se dá por meio de sua lavagem em hidróxido de sódio $(\mathrm{NaOH})$, capaz de promover a remoção de $\mathrm{CO}_{2}$ (RAPOSO et al., 2011).

A quantificação de biogás em escala laboratorial vem sendo comumente realizada a partir da dinâmica do deslocamento de fluidos, já que apresenta baixo custo, simplicidade e confiabilidade para quantificar baixas taxas de fluxo (GIRARDI NETO, 2014; KONRAD et al., 2016; MARTÍNEZ-SIBAJA et al., 2011). A quantificação se dá por meio da utilização de vasos comunicantes à um frasco abastecido de liquido, onde a pressão do fluxo de gases desloca o liquido, assim o volume de liquido deslocado será o mesmo que o de biogás produzido (GIRARDI NETO, 2014). 


\section{MATERIAIS E MÉTODOS}

O sistema de quantificação de biogás foi elaborado a partir do princípio do deslocamento de fluidos, através de dois frascos comunicantes (Figura 1). O líquido utilizado para preencher o medidor, foi uma solução de $\mathrm{NaOH}$ à $5 \%$, de modo a promover a lavagem do biogás através da dissolução do gás carbônico presente no mesmo. Foi adicionado indicador fenolftaleína no conjunto do medidor preenchido com $\mathrm{NaOH}$, proporcionando uma coloração rosa ao hidróxido de sódio, tornando visível o momento de saturação do $\mathrm{NaOH}$ por $\mathrm{CO}_{2}$ :

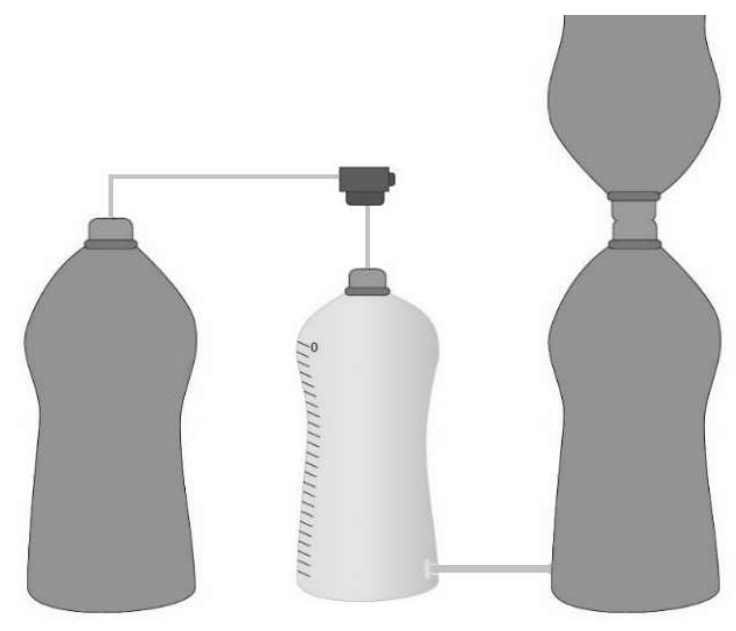

Figura 1: Biodigestor à esquerda e sistema de quantificação, frasco graduado ao centro e reservatório à direita. Fonte: Lourenço (2017).

Com um volume interno de $2,15 \mathrm{dm}^{3}$, os biodigestores foram elaborados por meio da reutilização de garrafas de Politereftalato de Etileno (PET), vedados com silicone acético incolor e envolvidos com folhas finas de alumínio, com saída apenas para o fluxo dos gases ao sistema de medição. Os volumes utilizados para alimentar os biodigestores, operados em batelada, foram obtidos através de um planejamento experimental $2^{3}$, resultando em oito pontos e um ponto central (PC), realizado em triplicata (Tabela 1):

Tabela 1: Alimentação dos Biodigestores.

\begin{tabular}{|c|c|c|c|c|c|c|c|c|}
\hline \multirow[t]{2}{*}{ Biodigestor } & \multicolumn{2}{|c|}{$\begin{array}{l}\text { Efluente da Parboilização de } \\
\text { Arroz }\end{array}$} & \multicolumn{2}{|c|}{$\begin{array}{l}\text { Efluente da Produção de } \\
\text { Laticínios }\end{array}$} & \multicolumn{2}{|c|}{$\begin{array}{l}\text { Lodo da Parboilização de } \\
\text { Arroz }\end{array}$} & \multicolumn{2}{|c|}{$\begin{array}{l}\text { Água } \\
\text { Destilada }\end{array}$} \\
\hline & [\%] & {$\left[\mathrm{dm}^{3}\right]$} & [\%] & {$\left[\mathrm{dm}^{3}\right]$} & [\%] & {$\left[\mathrm{dm}^{3}\right]$} & [\%] & {$\left[\mathrm{dm}^{3}\right]$} \\
\hline P1 & 40 & 0,680 & 10 & 0,170 & 20 & 0,340 & 30 & 0,510 \\
\hline $\mathrm{P} 2$ & 50 & 0,850 & 10 & 0,170 & 20 & 0,340 & 20 & 0,340 \\
\hline P3 & 40 & 0,680 & 20 & 0,340 & 20 & 0,340 & 20 & 0,340 \\
\hline P4 & 50 & 0,850 & 20 & 0,340 & 20 & 0,340 & 10 & 0,170 \\
\hline P5 & 40 & 0,680 & 10 & 0,170 & 30 & 0,510 & 20 & 0,340 \\
\hline P6 & 50 & 0,850 & 10 & 0,170 & 30 & 0,510 & 10 & 0,170 \\
\hline P7 & 40 & 0,680 & 20 & 0,340 & 30 & 0,510 & 10 & 0,170 \\
\hline P8 & 50 & 0,850 & 20 & 0,340 & 30 & 0,510 & 0 & 0,000 \\
\hline $\mathrm{PC}$ & 45 & 0,765 & 15 & 0,255 & 25 & 0,425 & 15 & 0,255 \\
\hline
\end{tabular}

O efluente e o lodo de arroz utilizados para alimentar os biodigestores foram fornecidos por uma indústria de arroz parboilizado localizada na cidade de Pelotas-RS, Brasil, já o efluente da produção de laticínios foi fornecido por uma indústria de laticínios, situada no mesmo município. Os substratos e o inóculo 
foram retirados do UASB (Upflow Anaerobic Sludge Blanket Reactor) das Estações de Tratamento de Efluente das indústrias.

Durante a execução do experimento, os biodigestores foram acomodados em banhos de aquecimento com termostato, à $35^{\circ} \mathrm{C}$, durante um período de 252 horas. As medições da produção de biogás foram realizadas ao fim das primeiras 12 horas e posteriormente em intervalos de 24 horas, zerando-se 0 medidor a cada intervalo. As análises de DQO e pH foram realizadas no Laboratório de Análise de Águas e Efluentes do Centro de Engenharias da Universidade Federal de Pelotas, de acordo com Standard Methods for the Examination of Water \& Wastewater (APHA, 2005).

\section{RESULTADOS}

Através dos gráficos presentes nas Figuras 2, 3 e 4 é possível observar a produção de metano nas primeiras 12 horas de experimentos e nos intervalos de 24 horas seguintes nos quais foram realizadas as quantificações da produção de biogás e cada sistema. No gráfico da Figura 5 pode ser observado as produções totais de metano ao fim das 252 horas de experimento. Os resultados das análises laboratoriais realizadas nesse estudo, DQO e pH, constam na Tabela 2 e na Figura 6, respectivamente.

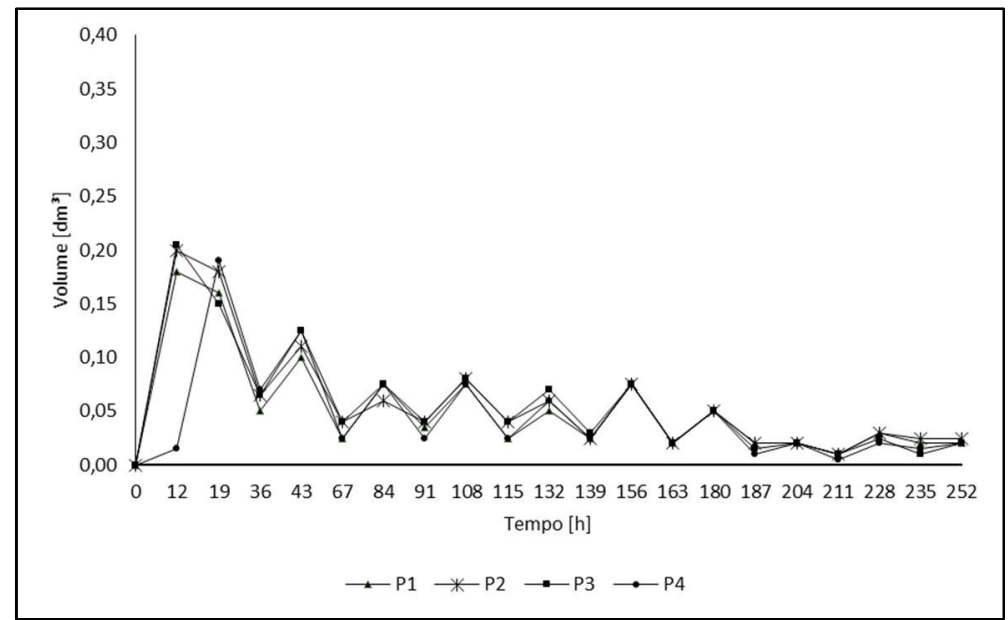

Figura 2: Gráfico da produção de metano nos biodigestores P1, P2, P3 e P4

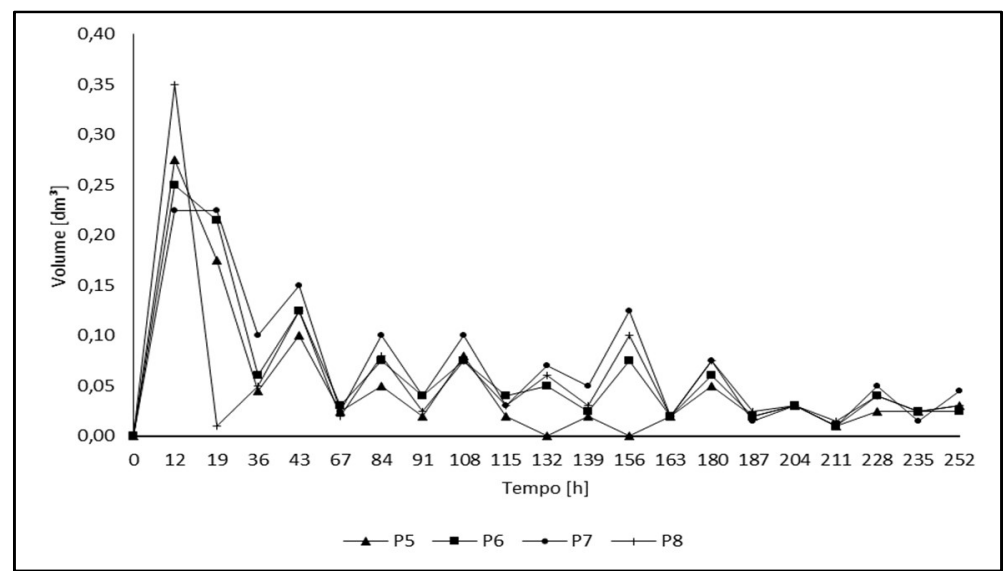

Figura 3: Gráfico da produção de metano nos biodigestores P5, P6, P7 e P8. 


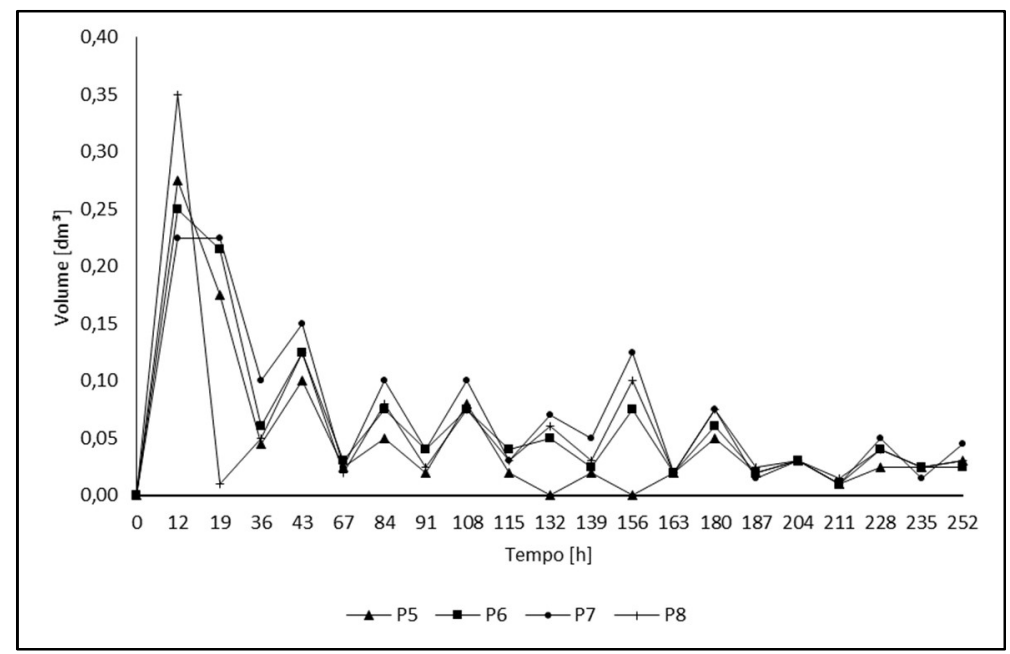

Figura 4: Gráfico da produção de metano nos biodigestores do ponto central.

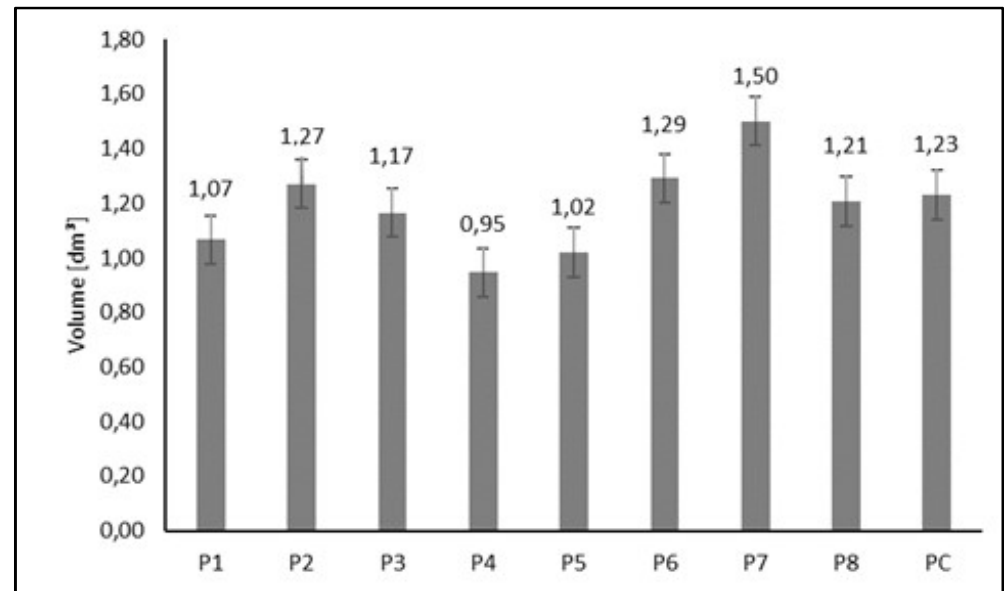

Figura 5: Gráfico da produção total de metano nos biodigestores.

Tabela 2: Resultados das Análises de DQO.

\begin{tabular}{|l|l|l|l|}
\hline Biodigestor & Entrada [mg/L] & Saída [mg/L] & Remoção [mg/L] \\
\hline P1 & 1333,33 & 744,19 & 589,14 \\
\hline P2 & 1600,00 & 992,25 & 607,75 \\
\hline P3 & 1466,67 & 868,22 & 598,45 \\
\hline P4 & 1600,00 & 878,54 & 721,47 \\
\hline P5 & 1802,22 & 1019,76 & 782,46 \\
\hline P6 & 1486,83 & 382,42 & 1104,41 \\
\hline P7 & 1599,47 & 372,09 & 1227,38 \\
\hline P8 & 1824,75 & 764,82 & 1059,93 \\
\hline PC & $2000,33 \pm 116,42$ & $1157,62 \pm 71,61$ & $842,71 \pm 107,54$ \\
\hline
\end{tabular}

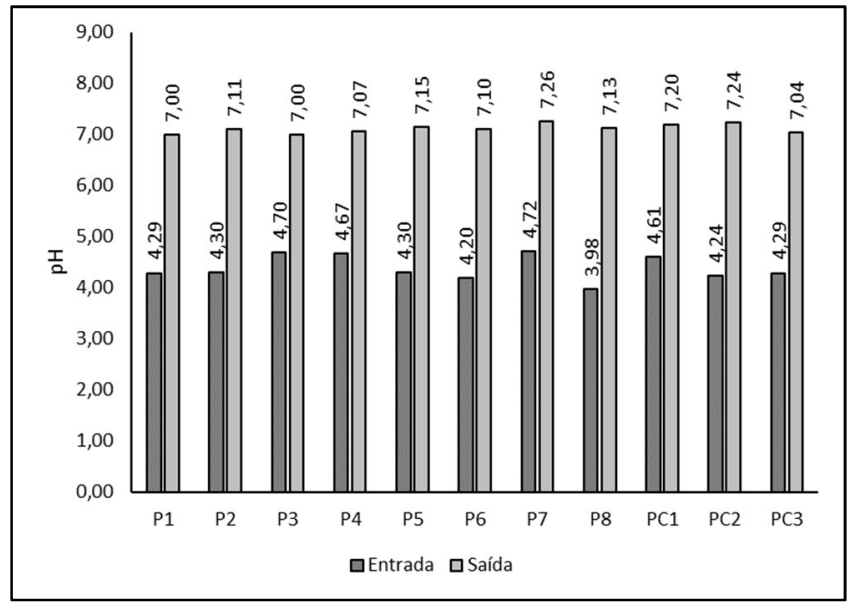

Figura 6: $\mathrm{pH}$ das amostras de entrada e saída dos biodigestores. 


\section{DISCUSSÃO}

Nas Figuras 1, 2 e 3 é possível observar que os biodigestores apresentaram comportamento semelhantes quanto à produção do gás, o pico de cada reator ocorreu entre 12 e 19 horas de experimento e a partir de 67 horas de atividade todos apresentaram estabilização da geração de metano seguido de queda de produção por volta de 163 horas.

O pico de produção nas primeiras 12 horas se dá, de acordo com a literatura, devido ao uso de inóculo do sistema, já que o mesmo garante a antecipação da partida inicial na produção de biogás e do pico de produção, possibilitando ainda a elevação do potencial de produção de biogás da biomassa (CERRILLO et al., 2017; LIU et al., 2017).

O ponto central, realizado em triplicata, apresentou um desvio padrão de $0,09 \mathrm{dm}^{3}$ tendo sido este adotado como erro do sistema de quantificação (Figura 5), resultando em um coeficiente de variação de 7,35\%. De acordo com os resultados apresentados na Figura 5, o biodigestor P7 apresentou uma maior produção de metano, com $1,5 \mathrm{dm}^{3}$, seguido do ponto $P 6$, com $1,29 \mathrm{dm}^{3}$. O ponto $P 7$ recebeu, dentro do delineamento experimental, alimentação máxima de inóculo e efluente de laticínios $20 \%$ e 30\%, respectivamente, e $40 \%$ de efluente da parboilização de arroz.

O biodigestor P4 foi o responsável pela menor produção, tendo tido uma alimentação de $50 \%$ de efluente de arroz e $20 \%$ de efluente de laticínios e lodo. Entretanto, ao considerar o erro referente ao sistema de quantificação do gás, as produções dos biodigestores P1, P2, P3, P4 e P5 não possuem diferença significativa. O mesmo ocorre com P6, P8 e PC.

A diferença nas produções pode ser consequência da alta carga orgânica proporcionada pelo efluente de arroz, característico no resultado da DQO de todos os biodigestores que receberam maior carga do efluente e baixo volume de inóculo de P1, P2, P3 e P4, quando comparado com P7, causando saturação de matéria orgânica no meio em relação ao potencial de biodegrabilidade do inóculo, inibindo a ação dos microrganismos.

Os processos anaeróbios de tratamento relacionam diretamente a remoção de $\mathrm{DQO}$ com a produção de metano (METCALF et al., 2016), sendo assim, espera-se que os biodigestores que removeram maiores cargas de DQO sejam os mesmos que produziram maiores volumes de metano, o que se validou na maioria dos biodigestores analisados neste trabalho (Tabela 2).

As maiores taxas de remoção ocorreram nos pontos P7 e P6, com remoção de $76,74 \%$ e $74,28 \%$. Em estudo realizado por Al-Malack et al. (2016) durante 72 dias em reator com volume útil de $20 \mathrm{dm}^{3}$, a digestão anaeróbia de efluente oriundo da indústria de laticínios gerou em seu melhor desempenho 1,6 $\mathrm{dm}^{3}$ por dia de biogás, removendo $55,80 \%$ de DQO. Já Peixoto et al. (2012) operou por $224 \mathrm{~h}$, à $25,0 \pm 0.9{ }^{\circ} \mathrm{C}$, processo fermentativo para tratamento de efluente da produção de arroz, alcançando uma remoção de 63,91\%, em um reator com capacidade para $1 \mathrm{dm}^{3}$ de líquido e $1 \mathrm{dm}^{3}$ de headspace. Nadaleti et al. (2018), obtiveram uma produção de 5,198 dm³ de biogás através da biodigestão anaeróbia de efluente e lodo da parboilização do arroz, em biodigestores semelhantes aos utilizados neste estudo operados à $35^{\circ} \mathrm{C}$ por 276 horas. 
Sobre às análises de $\mathrm{pH}$ de entrada e saída, todos os processos apresentaram comportamento semelhante, acidez em suas amostras de entrada, em torno de 4,0, e neutralidade em suas saídas (Figura 6). Segundo Khalid et al. (2011), o pH ideal para o desenvolvimento de bactérias metanogênicas se encontra na neutralidade, sendo assim o pH pode ter causado interferências negativas na produção de biogás.

\section{CONCLUSÕES}

Determinou-se que a melhor proporção dos substratos e inóculo para a produção de metano via codigestão ocorreu, nesse estudo, na alimentação com $40 \%$ e $20 \%$ de efluente da indústria de arroz parboilizado e do efluente da produção de laticínios, respectivamente, e $30 \%$ do lodo da indústria de arroz. O processo de codigestão anaeróbia se mostrou eficaz na neutralização do pH e na remoção de DQO, com remoções de até $76,74 \%$. Ademais, o sistema de quantificação de gases utilizado no estudo demonstrou grande eficácia, com desvio padrão de $0,9 \mathrm{dm}^{3}$ e coeficiente de variação de $7,35 \%$.

\section{REFERÊNCIAS}

AGDAG, O.; SPONZA, D.. Co-digestion of mixed industrial sludge with municipal solid wastes in anaerobic simulated landfilling bioreactors. Journal of Hazardous Materials, v.140, n.1-2, p.75-85, 2007. Dol: http://doi.org/10.1016/j.jhazmat.2006.06.059

AL-MALACK, M. H.; ALDANA, G. R.. Performance of anaerobic immersed membrane bioreactor (AnIMBR) treating synthetic dairy wastewater. Desalination and Water Treatment, v.57, n.46, p.22200-22211, 2016. DOI: http://doi.org/10.1080/19443994.2015.1129514

AMATO, G. W.. Arroz no programa mundial de alimentação das Nações Unidas. 2 ed. Porto Alegre: Instituto Rio Grandense do Arroz, 2017.

AMATO, G. W.; BITTENCOURT, D. M.; GUINDANI, A. C.. Parboilização do arroz parâmetros de encharcamento. Porto Alegre: CIENTEC. Boletim Técnico, v.19, p.120, 1989.

APHA. American Public Health Association. Standard Methods for the Examination of Water and Wastewater: Method 5220-C, 2005; Introduction 4500-N A, 2005.

ANJUM, M.; KHALID, A.; QADEER, S.; MIANDAD, R.. Synergistic effect of co-digestion to enhance anaerobic degradation of catering waste and orange peel for biogas production. Waste Management \& Research, v.35, n.9, p.967-977, 2017. DOI: http://doi.org/10.1177/0734242X17715904

BASTOS, R. G.; SEVERO, M.; VOLPATO, G.; JACOB-LOPES, E.; ZEPKA, L. Q.; QUEIROZ, M. I.. Bioconversão do nitrogênio do efluente da parboilização do arroz por incorporação em biomassa da cianobactéria Aphanothece microscópica Nägeli. Revista Ambiente e Água, v.5, n.3, 2010. DOI: http://doi.org/10.1155/2012/490647

CASTRO, G. M.; SCHWANTES, D.; JUNIOR, A. C. G.; RICHART, A.; VEIGA, T. G.; ROSENVERGER, A. G.. Treatment of dairy effluents in wetlands systems with floating aquatic macrophytes. Revista de Ciências Ambientais, v.11, n.2, 2017. DOI: http://dx.doi.org/10.18316/rca.v11i2.2765

CERRILLO, M.; VIÑAS, M.; BONMATÍ, A.. Start-up of electromethanogenic microbial electrolysis cells with two diferent biomass inocula for biogas upgrading. ACS Sustainable Chemistry \& Engineering, v.5, n.10, p.88528859, 2017. DOI: http://doi.org/10.1021/acssuschemeng.7b01636

CONAB. Companhia Nacional de Abastecimento. Acompanhamento da Safra Brasileira de Grãos: v.4: SAFRA 2016/17: n.11: Décimo primeiro levantamento. Brasília: CONAB, 2017.

FAO. Food and Agriculture Organization of the United Nations. Dairy Market Review: Milk production trends in 2017. 2018.

FAO. Food and Agriculture Organization of the United Nations. Milk and Milk Products: Price and Trade Update. 2017.

GAIDA, D.; WOLF, C.; BONGARDS, M.. Feed control of anaerobic digestion processes for renewable energy production: A review. Renewable and Sustainable Energy Reviews, v.68, p.869-875, 2017. DOI: http://doi.org/10.1016/j.rser.2016.06.096

GIRARDI NETO, J.; SANTOS, V. G.; ANDREGUETTO, L. G.; LANGE, G. H.; SILVA, J. D.; VALLE, J. A. B.; PINHEIRO, I. G. Quantificação de Biogás em Reatores Anaeróbios através do Método de Deslocamento de Volume de Água. Revista de estudos ambientais (online), v.16, n.1, p.45-53, 2014. DOI: http://dx.doi.org/10.7867/1983-1501.2014v16n1p45-53

GOLUNSKI, S. M.; MULINARI, J.; CAMARGO, A. F.; VENTURIN, B.; BALDISSARELLI, D. P.; MARQUES, C. T.; VARGAS, G. D. L. P.; COLLA, L. M.; MOSSI, A.; TREICHEL, H.. Ultrasound effects on the activity of Aspergillus Niger lipases in their application in dairy wastewater treatment. Environ QualManage, v.27, 
n.1, p.95-101, 2017. DOI:

http://doi.org/10.1002/tqem.21508

GRANDO, R. L.; ANTUNE, A. M. S.; FONSEXA, F. V.; SÁNCHEZ, A.; BARRENA, R.; FONT, X.. Technology overview of biogas production in anaerobic digestion plants: A European evaluation of research and development. Renewable and Sustainable Energy Reviews, v.80, p.44-53, 2017. DOI: http://doi.org/10.1016/j.rser.2017.05.079

HIROTA, K.; YOKATA, Y.; SEKIMURA, T; UCHIUMI, H.; GUO, Y.; OHTA, H.; YUMOTO, I.. Bacterial communities in different locations, seasons and segments of a dairy wastewater treatment system consisting of six segments. Journal of Environmental Sciences, v.36, p.109-115, 2016. DOI: http://doi.org/10.1016/i.jes.2015.09.025

IBGE. Instituto Brasileiro de Geografia e Estatística. Levantamento Sistemático da Produção Agrícola: Pesquisa Mensal de Previsão e Acompanhamento das Safras Agrícolas no Ano Civil. Rio de Janeiro, 2017.

KHALID, A.; ARSHAD, M.; ANJUM, M.; MAHMOOD, T.; DAWSON, L.. The anaerobic digestion of solid organic waste. Waste Management, v.31, p.1737-1744, 2011. DOI: http://doi.org/10.1016/j.wasman.2011.03.021

KONRAD, O.; BEZAMA, A. B.; PRADE, T. BACKES, G. M.; OECHSNER, H.. Enhancing the analytical capacity for biogas development in Brazil: assessment of an original measurement system for low biogas flow rates out of agricultural biomass residues. Eng. Agríc., v.36, n.5, 2016. DOI: http://dx.doi.org/10.1590/1809-4430Eng.Agric.v36n5p792-798/2016

KOTHARI, R.; KUMAR, V.; PATHAK, V. V.; TYAGI, V. V.. Sequential hydrogen and methane production with simultaneous treatment of dairy industry wastewater: Bioenergy profit approach. International Journal of Hydrogen Energy, v.42, n.8, p.4870-4879, 2017. DOI: http://doi.org/10.1016/j.ijhydene.2016.11.163

KUMAR, A.; PRIYADARSHINEE, R.; ROY, A.; DASGUPTA, D.; MANDAL, T.. Current techniques in rice mill effluent treatment: Emerging opportunities for waste reuse and waste-to-energy conversion. Chemosphere, v.164, p.404412, 2016. DOI:

http://doi.org/10.1016/j.chemosphere.2016.08.118

LEKSHMISREE, A. S.; VIJAYAN, N.. Treatment of Dairy Industry Waste Water Using Fungal Consortium. International Research Journal of Engineering and Technology (IRJET), v.3, n.8, p.1924-1929, 2016.

LIU, T.; SUN, L.; SCÜNURER, B. M. A.. Importance of inoculum source and initial community structure for biogas production from agricultural substrates. Bioresource Technology, v.245, p.768-777, 2017. DOI: http://doi.org/10.1016/i.biortech.2017.08.213

LOURENÇO, V. A.. Produção de biogás via co-digestão anaeróbia de efluente da parboilização do arroz e resíduos sólidos orgânicos. Monografia ( Graduação em Engenharia Ambiental e Sanitária) - Universidade Federal de Pelotas, Pelotas, 2017.
MAO, C.; FENG, Y.; WANG, X.; REN, G.. Review on research achievements of biogas from anaerobic digestion.

Renewable and Sustainable Energy Reviews, v.45, p.540555, 2015. DOI: http://doi.org/10.1016/i.rser.2015.02.032

MARAGKAKI, A. E.; FOUNTOULAKIS, M.; GYPAKIS, A.; KYRIAKOU, A.; LASARIDI, K. M.. Pilot-scale anaerobic codigestion of sewage sludge with agro-industrial by-products for increased biogas production of existing digesters at wastewater treatment plants. Waste Management, v.59, p.362-370, 2017. DOI: http://doi.org/10.1016/i.wasman.2016.10.043

MARTÍNEZ-SIBAJA, A.; ALVARADO-LASSMAN, A.; ASTORGAZARAGOZA, C. M.; ADAM-MEDINA, M.; POSADA-GÓMEZ, R.; RODRÍGUEZ-JARQUIN, J. P.. Volumetric gas meter for laboratory-scale anaerobic bioreactors. Measurement, v.44, p.1801-1805, 2011. DOI:

http://doi.org/10.1016/j.measurement.2011.08.018

METCALF, L.; EDDY, H. P.. Tratamento de Efluentes e

Recuperação de Recursos. Brasília: McGraw Hill Brasil, 2016.

NADALETI, W. C.; LOURENÇO, V. A.; SCHOELER, G. P.; AFONSO, M; SANTOS, R. F.; VIEIRA, B. M.; LEANDRO, D.; QUADRO, M. S.. Temperaturas mesófilas e termófilas na produção de Biogás através de efluente da parboilização do arroz. Revista Brasileira de Engenharia e Sustentabilidade, v.5, n.1, p.17-21, 2018. DOI:

http://dx.doi.org/10.15210/rbes.v5i1.12540

NADALETI, W. C.; PRZYBYLA, G.. Emissions and performance of a spark-ignition gas engine generator operating with hydrogen-rich syngas, methane and biogas blends for application in southern Brazilian rice industries. Energy, v.154, p.38-51, 2018. DOI:

http://doi.org/10.1016/j.energy.2018.04.046

NESHAT, S. A.; MOHAMMADI, M.; NAJAFPOUR, G. D.; LAHIJANI, P.. Anaerobic co-digestion of animal manures and lignocellulosic residues as a potent approach for sustainable biogas production. Renewable and Sustainable Energy Reviews, v.79, p.308-322, 2017. DOI: http://doi.org/10.1016/i.rser.2017.05.137

PARAGINSKI, R. T.; ZIEGLERM, V.; TALHAMENTO, A.; ELIAS, M. C.. Propriedades tecnológicas e de cocção em grãos de arroz condicionados em diferentes temperaturas antes da parboilização. Brazilian Journal of Food Technology, Campinas, v.17, n.2, p.146-453, 2014. DOI: http://dx.doi.org/10.1590/bjft.2014.021

PAZUCH, F. A.; SIQUEIRA, J.; FRIEDRICH, L.; LENZ, A. M.; NOGUEIRA, C. E. C.; SOUZA, S. N. M.. Co-digestion of crude glycerin associated with cattle manure in biogas production in the State of Paraná, Brazil. Acta Scientiarum. Technology, Maringá, v.39, n.2, p.149-159, 2017. DOI: http://dx.doi.org/10.4025/actascitechnol.v39i2.29167

PEIXOTO, G.; PANJOTA FILHO, J. L. R.; AGNELLI, J. A. B.; BARBOZA, M.; ZAIAT, M.. Hydrogen and Methane Production, Energy Recovery, and Organic Matter Removal from Effluents in a Two-Stage Fermentative Process. Applied Biochemistry and Biotechnology, v.168, n.3, p.651-671, 2012. 
QUEIROZ, M. I.; LOPES, E. J.; ZEPKA, L. Q.; BASTOS, R. G.; GOLDBECK, R.. The kinetics of the removal of nitrogen and organic matter from parboiled rice effluent by cyanobacteria in a stirred batch reactor. Bioresource Technology, v.98, p.2163-2169, 2007. DOI: http://doi.org/10.1016/j.biortech.2006.08.034

RAPOSO, F.; FERNÁNDEZ-CEGRÍ, V.; RUBIA, M. A.; BORJA, R.; BÉLINE, F.; CAVINATO, C.; DEMIRER, G.; FERNÁNDEZ, B.; FERNÁDEZ-POLANCO, M.; FRIGON, J. C.; GANESH, R. KAPARAJU, P.; KOUBOVA, J.; MÉNDEZ, R.; MNIN, G.; PEENE, A.; SCHERER, P.; TORRIJOS, M.; UELLENDAHL, H.; WIERINCK, I; WILDE, V.. Biochemical methane potential (BMP) of solid organic substrates: evaluation of anaerobic biodegradability using data from an international interlaboratory study. Journal of Chemical Technology \& Biotechnology, v.86, n.8, 2011. DOI: http://doi.org/10.1002/jctb.2622

RYCKEBOSCH, E.; DROUILLON, M.; VERVAEREN, H.. Techniques for transformation of biogas to biomethane. Biomass and Bioenergy, v.35; p.1633-1645, 2011. DOI: http://doi.org/10.1016/i.biombioe.2011.02.033

SANTOS, D. G.; TURNES, C. G.; CONCEIÇÃO, F. R.. Bioremediation of Parboiled Rice Effluent Supplemented with Biodiesel-Derived Glycerol Using Pichia pastoris X-33. Scientific World Journal, v.2012, 2012. DOI: http://doi.org/10.1100/2012/492925

SPINOSA, W. A.; JÚNIOR, V. S.; GALVAN, D.; FIORIO, J. L.; GOMEZ, R. J. H. C.. Syrup production via enzymatic conversion of a byproduct (broken rice) from rice industry. Acta Scientiarum Technology, Maringá, v.38, n.1, p.13-22, 2016. DOI:

http://dx.doi.org/10.4025/actascitechnol.v38i1.26700

STATISTA. The Statista Portal. Agriculture: Quantity of rice produced in Brazil from 2010 to 2017. 2018.

THAKUR, A. B.; RIKTA. S. Y.; EASHA, N. J.; SIDDIK, M. A. B.; UDDIN, M. K.. Physicochemical Composition of the Household Solid Waste and Prospect for Biogas Production. J. Environ. Sci. \& Natural Resources, Bangladesh, v.9, n.2, p.151-154, 2016. DOI:

http://dx.doi.org/10.3329/jesnr.v9i2.32186

USDA. United States Department of Agriculture: Foreign Agricultural Service. Brazil Dairy and Products Annual: Annual Dairy Report. 2017.

A CBPC - Companhia Brasileira de Produção Científica (CNPJ: 11.221.422/0001-03) detém os direitos materiais desta publicação. Os direitos referem-se à publicação do trabalho em qualquer parte do mundo, incluindo os direitos às renovações, expansões e disseminações da contribuição, bem como outros direitos subsidiários. Todos os trabalhos publicados eletronicamente poderão posteriormente ser publicados em coletâneas impressas sob coordenação da Sustenere Publishing, da Companhia Brasileira de Produção Científica e seus parceiros autorizados. Os (as) autores (as) preservam os direitos autorais, mas não têm permissão para a publicação da contribuição em outro meio, impresso ou digital, em português ou em tradução. 